\title{
Bleeding control in endoscopic sinus surgery: a systematic review of the literature*
}

\author{
A. Rodríguez Valiente, A. Roldán Fidalgo, D. Laguna Ortega Rhinology 51:298-305, 2013 \\ DOl:10.4193/Rhino12.048 \\ Department of Otorhinolaryngology, University Hospital Puerta de Hierro, Madrid, Spain \\ *Received for publication: \\ March 18, 2012 \\ Accepted: July 28, 2013
}

\begin{abstract}
Summary
In the literature various methods are described to reduce bleeding in endoscopic sinus surgery. Scientific evidence and results were gathered and analysed to determine the effectiveness of the various methods used. A total of 20 articles fulfilled the inclusion criteria. Two retrospective articles studied the differences between local and general anaesthesia. Three articles analysed the use of local methods to control bleeding. The majority of the articles analysed the use of different systemic drugs to control intraoperative bleeding.

Certain procedures, such as the reverse Trendelenburg position, the use of high doses of epinephrine, the infiltration of phenylephrine and lidocaine into the pterygopalatine fossa, the preoperative use of prednisone, and the control of the heart rate (with dexmedetomidine or remifentanil), appear to reduce the intraoperative blood loss and/or improve the visualisation of the surgical field. However, the evidence supporting these conclusions is poor. The benefits of other procedures, such as the preoperative use of $\beta$-blockers, antihypertensive agents, and surgical pledgets with oxymetazoline, phenylephrine, or cocaine, for bleeding control are not evidenced in the literature. In addition, the literature does not present any evidence on the benefits of local anaesthesia compared with general anaesthesia or the use of propofol compared to inhaled analgesics in terms of intraoperative bleeding or complication rates.
\end{abstract}

Key words: paranasal sinuses, nasal cavity, haemorrhage, surgery, endoscopy

\section{Introduction}

Surgical bleeding has always been one of the major primary concerns of surgeons and an important factor in both the duration and the results of surgery. Bleeding hinders adequate visualisation of the surgical field (VSF) and thus increases the rate of complications ${ }^{(1-4)}$, occasionally requires suspension of the intervention ${ }^{(3,4)}$, and can even put the patient's life at risk. Surgical bleeding is even more relevant in otorhinolaryngology. Many of the techniques used in other parts of the body to control bleeding cannot be used in surgery of the nasal cavities and paranasal sinuses, specifically during endoscopic sinus surgery (ESS). This is a zone in which access is not ample, because it is normally available through a nostril. In addition, in this type of surgery, the surgeon can only use one hand to perform the work because the other one holds the optic tube. Increased bleeding in this area results in a poorer display of the different structures and anatomical landmarks. The potential complications include damage to the arterial skull base, cerebrospinal fluid leakage, penetration of the orbit, and damage to the optic nerve and the internal carotid artery ${ }^{(5-8)}$.

It has been proposed that improved VSF could result in reduced surgical time, faster postoperative recovery, reduced relapse rate, and less complications.

Despite the particular importance of bleeding control during surgery, the relevant published literature is not very extensive, 
particularly in the fields of otorhinolaryngology and especially ESS.

A literature review of the different methods used for bleeding control in ESS was thus performed. The available scientific evidence was analysed to ascertain the efficacy of the different methods used and to elucidate any possible differences among the various strategies that are currently available.

\section{Material and methods}

A literature review of all of the articles published through January 2012 on the topic of the control of bleeding in endoscopic sinus surgery was performed.

\section{Search strategy}

The search was conducted using the following MeSH terms: "Paranasal sinuses", "Nasal cavity", "Haemorrhage", "Surgery", "Endoscopy", "Blood Loss", "Endoscopy", "Otorhinolaryngologic Surgical Procedures", "Rhinitis", "Sinusitis", "Paranasal Sinus Diseases,, "Postoperative Complications", and "Treatment Outcome".

The search was first conducted using the databases of clinical practise guidelines (National Guideline Clearinghouse, NHS Guidelines Finder, CMA Infobase), and this search yielded no bibliographical references. Subsequently, systematic reviews were performed (Clinical Evidence, The Cochrane Library, DARE), but no results were obtained from these databases either. A review of original articles in PubMed was then performed, and the articles identified during this search process were then analysed to add supplementary references.

\section{Selection criteria}

Once all of the abstracts were obtained, the studies that measured bleeding control in ESS were selected. The studies that were not directly related to bleeding control, the studies that measured bleeding in other areas aside from the nasal cavity and paranasal sinuses, and the studies that involved septoplasty or any other surgical technique aside from functional ESS were discarded.

Subsequently, all of the selected articles, including the results, were critically read, and the levels of evidence presented by the articles were compared.

\section{Results}

A total of 20 articles met the inclusion criteria. According to the Agency for Healthcare Research and Quality, 15 and five of these articles exhibited an Ib and III level of evidence, respectively (Table 1). In practical terms, the articles could be grouped into four sections based on bleeding control mechanisms discussed: A) studies comparing local and general anaesthesia, B) studies controlling positional factors, C) studies using local methods, and D) studies comparing systemic drugs.
A) Studies comparing local and general anaesthesia Three retrospective studies considered the differences between local and general anaesthesia. Stankiewicz ${ }^{(9)}$ and Gittelman et al. ${ }^{(10)}$ concluded that the use of general anaesthesia could be associated with greater blood loss and a longer operation time. Nevertheless, this higher bleeding did not entail an increase in the number of complications nor in the seriousness thereof ${ }^{(9)}$; rather, the use of general anaesthesia might even have reduced the number of complications ${ }^{(10)}$. Gross et al. ${ }^{(11)}$ found that cases performed under general anaesthesia displayed a significantly higher complication rate compared with cases performed under local anaesthesia. This finding was attributed to an increased bleeding rate under general anaesthesia, which was most likely due to the fewer local injections of epinephrine and the vasodilatory effect of general anaesthesia.

\section{B) Studies controlling positional factors}

Only one study attempted to validate the relationship between positional factors and the volume of blood loss. In the study conducted by Ko et al. ${ }^{(12)}$, the patients were randomly categorised into two groups: the $10^{\circ}$ reverse Trendelenburg position group and the completely reclining control group. Three types of methods were used to assess the blood loss: the total blood loss calculated in the suction bottle, the blood loss per minute, and a blood loss scale from 0 to 5 . The authors found that the reverse Trendelenburg position reduced the blood loss and significantly improved the VSF but not the operation time.

\section{C) Studies using local methods}

Three studies assessed local methods to reduce bleeding in ESS. All of these studies were prospective, randomised, double-blind studies ${ }^{(13-15)}$, and one of the studies was controlled ${ }^{(15)}$.

Riegle et al. ${ }^{(13)}$ compared the preoperative and intraoperative use of pledgets saturated with oxymetazoline $(0.05 \%)$, phenylephrine $(0.25 \%)$, or cocaine $(4 \%)$ in children. These researchers subjectively concluded that there was less bleeding and better VSF with the use of oxymetazoline but found no differences in terms of the total bleeding or the surgical time.

Sarmento et al. ${ }^{(14)}$ compared different concentrations (1:2,000, $1: 10,000$ and 1:50,000) of topical epinephrine solutions. The patients were divided into three groups. All of the patients were administered prednisone ( $40 \mathrm{mg} /$ day) for five days before surgery. The evaluation of bleeding was measured by the volume of aspirated blood, the surgeon's grade (from $A$ to $D$ ), and a visual analogue scale by the surgeon ("no bleeding" to "extreme bleeding"). The total quantity of epinephrine that was administered was $400 \mu \mathrm{g}$ in the 1:50,000 solution, 2,000 $\mu \mathrm{g}(2 \mathrm{mg})$ in the $1: 10,000$ solution, and $10,000 \mu \mathrm{g}(10 \mathrm{mg})$ in the $1: 2,000$ solution. There was a gradual increase in the plasma levels of epinephrine in all of the groups. These levels were higher in the group that was administered the 1:2,000 solution of adrenaline. 
Table 1. Bleeding control in endoscopic sinus surgery.

\begin{tabular}{|c|c|c|c|c|c|c|c|c|}
\hline Study & Trial Design & $\begin{array}{l}\text { Evidence } \\
\text { Level }\end{array}$ & Drugs Used & Bleeding & VSF & $\begin{array}{l}\text { Measureme } \\
\text { Opera- } \\
\text { tion time }\end{array}$ & HR & MABP \\
\hline $\begin{array}{l}\text { Stankiewicz } \\
{(1989)^{(9)}}^{(198}\end{array}$ & Retrospective & III & General vs. Local Anaesthesia & + & & + & & \\
\hline $\begin{array}{l}\text { Gittelman } \\
(1993)^{(10)}\end{array}$ & Retrospective & III & General vs. Local Anaesthesia & + & & + & & \\
\hline $\begin{array}{l}\text { Gross } \\
(1997)^{(11)}\end{array}$ & Retrospective & III & General vs. Local Anaesthesia & + & & & & \\
\hline $\begin{array}{c}\text { Ko } \\
(2008)^{(12)}\end{array}$ & $\begin{array}{l}\text { Prospective } \\
\text { Controlled } \\
\text { Randomised }\end{array}$ & $\mathrm{lb}$ & $\begin{array}{l}\text { Reverse Trendelenburg } \\
\text { Position vs. Completely Laid }\end{array}$ & + & + & + & & + \\
\hline $\begin{array}{l}\text { Riegle } \\
(1992)^{(13)}\end{array}$ & $\begin{array}{l}\text { Prospective } \\
\text { Randomised } \\
\text { Double-blind } \\
\text { In children }\end{array}$ & $\mathrm{lb}$ & $\begin{array}{l}\text { Pledgets Saturated With } \\
\text { 1. Oxymetazoline } \\
\text { 2. Phenylephrine } \\
\text { 3. Cocaine }\end{array}$ & + & + & + & & \\
\hline $\begin{array}{l}\text { Sarmento } \\
(2009)^{(14)}\end{array}$ & $\begin{array}{l}\text { Prospective } \\
\text { Randomised } \\
\text { Double-blind }\end{array}$ & $\mathrm{lb}$ & $\begin{array}{l}\text { Topical Adrenaline: } \\
\text { 1:2000; 1:10000; 1:50000 }\end{array}$ & + & & + & + & \\
\hline $\begin{array}{l}\text { Wormald } \\
(2005)^{(15)}\end{array}$ & $\begin{array}{l}\text { Prospective } \\
\text { Controlled } \\
\text { Randomised } \\
\text { Double-blind }\end{array}$ & $\mathrm{lb}$ & $\begin{array}{c}\text { 1. Epinephrine + Lidocaine Infil- } \\
\text { tration } \\
\text { 2. Control Group }\end{array}$ & & + & + & + & + \\
\hline $\begin{array}{l}\text { Sieskiewicz } \\
\left(_{(2006)}\right)^{(2)}\end{array}$ & $\begin{array}{l}\text { Prospective } \\
\text { Randomised } \\
\text { Blind }\end{array}$ & $\mathrm{lb}$ & $\begin{array}{l}\text { 1. Prednisone } \\
\text { 2. Control Group }\end{array}$ & + & + & + & + & + \\
\hline $\begin{array}{l}\text { Nair } \\
(2004)^{(16)}\end{array}$ & $\begin{array}{l}\text { Prospective } \\
\text { Randomised } \\
\text { Double blind }\end{array}$ & $\mathrm{lb}$ & $\begin{array}{l}\text { 1. Preoperative } \beta \text {-blocker (Meto- } \\
\text { prolol) } \\
\text { 2. Control Group }\end{array}$ & + & + & & + & + \\
\hline $\begin{array}{l}\text { Jacobi } \\
(2000)^{(21)}\end{array}$ & $\begin{array}{l}\text { Prospective } \\
\text { Randomised } \\
\text { Blinded }\end{array}$ & $\mathrm{lb}$ & $\begin{array}{l}\text { 1. Sodium Nitroprusside } \\
\text { 2. Control Group }\end{array}$ & + & + & & + & + \\
\hline $\begin{array}{l}\text { Boezaart } \\
(1995)^{(19)}\end{array}$ & $\begin{array}{l}\text { Prospective } \\
\text { Randomised } \\
\text { Blinded }\end{array}$ & $\mathrm{lb}$ & $\begin{array}{l}\text { 1. Sodium Nitroprusside } \\
\text { 2. Esmolol }\end{array}$ & + & + & & & + \\
\hline $\begin{array}{l}\text { Guven } \\
(2011)^{(22)}\end{array}$ & $\begin{array}{l}\text { Prospective } \\
\text { Cotrolled } \\
\text { Randomised } \\
\text { Blinded }\end{array}$ & $\mathrm{lb}$ & $\begin{array}{l}\text { 1. Dexmedetomidine } \\
\text { 2. Control Group }\end{array}$ & + & + & + & + & + \\
\hline $\begin{array}{c}\text { Beule } \\
(2007)^{(23)}\end{array}$ & $\begin{array}{l}\text { Prospective } \\
\text { Controlled } \\
\text { Randomised } \\
\text { Double-blind }\end{array}$ & $\mathrm{lb}$ & $\begin{array}{l}\text { 1. Propofol + Fentanyl } \\
\text { 2. Sevoflurane + Fentanyl }\end{array}$ & + & + & + & + & + \\
\hline $\begin{array}{l}\text { Manola } \\
(2005)^{(24)}\end{array}$ & Retrospective & III & $\begin{array}{l}\text { 1. Propofol + Remifentanil } \\
\text { 2. Sevoflurane + Sufentanil } \\
\text { 3. Isoflurane + Fentanyl }\end{array}$ & + & + & & & + \\
\hline $\begin{array}{l}\text { Wormald } \\
(2005)^{(20)}\end{array}$ & $\begin{array}{l}\text { Prospective } \\
\text { Controlled } \\
\text { Randomised }\end{array}$ & $\mathrm{lb}$ & $\begin{array}{l}\text { 1. Propofol + Remifentanil } \\
\text { 2. Sevoflurane + Fentanyl }\end{array}$ & & + & + & + & + \\
\hline $\begin{array}{l}\text { Eberhart } \\
(2003)^{(17)}\end{array}$ & $\begin{array}{l}\text { Prospective } \\
\text { Randomised } \\
\text { Double-blind }\end{array}$ & $\mathrm{lb}$ & $\begin{array}{l}\text { 1. Propofol + Remifentanil } \\
\text { 2. Isoflurane + Alfentanil }\end{array}$ & + & + & & + & + \\
\hline $\begin{array}{l}\text { Pavlin } \\
(1999)^{(25)}\end{array}$ & $\begin{array}{l}\text { Prospective } \\
\text { Blinded }\end{array}$ & $\mathrm{lb}$ & $\begin{array}{l}\text { 1. Propofol + Alfentanil } \\
\text { 2. Isoflurane + Alfentanil }\end{array}$ & + & + & & & \\
\hline $\begin{array}{l}\text { Blackwell } \\
(1993)^{(26)}\end{array}$ & Retrospective & III & $\begin{array}{l}\text { 1. Propofol + Fentanyl/Alfentanil } \\
\text { 2. Isoflurane + Fentanyl/Alfentanil }\end{array}$ & + & & & & + \\
\hline $\begin{array}{c}\text { Ahn } \\
(2007)^{(27)}\end{array}$ & $\begin{array}{l}\text { Prospective } \\
\text { Randomised } \\
\text { Double-blind }\end{array}$ & $\mathrm{lb}$ & $\begin{array}{l}\text { 1.Sevoflorane + Remifentanil } \\
\text { 2. Propofol + Remifentanil }\end{array}$ & + & + & & + & + \\
\hline $\begin{array}{c}\text { Tirelli } \\
(2004)^{(28)}\end{array}$ & $\begin{array}{l}\text { Prospective } \\
\text { Randomised } \\
\text { Blinded }\end{array}$ & $\mathrm{lb}$ & $\begin{array}{l}\text { 1. Remifentanil + Propofol } \\
\text { 2. Isofluorane + Fentanyl }\end{array}$ & + & + & & + & + \\
\hline
\end{tabular}

VSF: visualisation of the surgical field; HR: heart rate; MABP: mean arterial blood pressure. 
Greater numbers of hypertension peaks were found in the more concentrated epinephrine groups, and these increased as the surgery progressed. The study concluded that the operation time was not significantly different among the three groups. The group that was administered the 1:2,000 dose of epinephrine experienced less bleeding. None of the groups exhibited heart rate $(H R)$ measurements that were significantly beyond the normal limits.

Wormald et al. ${ }^{(15)}$ discussed the usefulness of the preoperative infiltration of epinephrine and lidocaine into the pterygopalatine fossa, which results in an improvement in the VSF of the infiltrated side. The study noted a relationship between the heart rate (HR) and the VSF, i.e., the VSF improved as the HR decreased. This same relationship was found by Nair et al. ${ }^{(16)}$ and by Eberhart et al. ${ }^{(17)}$. However, this relationship was not found with the mean arterial blood pressure (MABP). There was also an association between the operation time and the VSF: a higher surgical time resulted in worse VSF.

\section{D) Studies comparing systemic drugs}

\section{D1) Preoperative steroids}

Sieskiewicz et al. ${ }^{(2)}$ investigated the effects of oral steroid therapy on the improvement of surgical field conditions. The patients in group 1 received prednisone at a dose of $30 \mathrm{mg} / \mathrm{d}$ for five consecutive days. The patients in group 2 did not receive any steroids for at least six months prior to surgery. Both groups were administered the same presurgical, induction, and maintenance anaesthesia. The intensity of bleeding was estimated according to the scales described by Fromme ${ }^{(18)}$ and Boezaart ${ }^{(19)}$. No significant differences were found in the MABP, HR, or total blood loss. Nevertheless, the VSF was significantly improved and the operation time was significantly shorter in the group that was administered steroids.

\section{D2) Drugs with hypotensive effects}

Nair et al. ${ }^{(16)}$ analysed the effects of a preoperative administration of a $\beta$-blocker (metoprolol) on the reduction of the MABP compared with a control group. During the first hours of surgery, both the HR and MABP were lower in patients who had been administered the $\beta$-blocker, and no differences were observed in the VSF or total bleeding between the groups. Thus, these researchers found a lower HR, an improved VSF, and no association with MABP $(16,17,20)$.

Two studies compared the hypotensive effects of sodium nitroprusside (SNP) ${ }^{(19,21)}$ and esmolol ${ }^{(19)}$. Jacobi et al. ${ }^{(21)}$ did not find any differences in the total bleeding, VSF, or HR between the group administered SNP and a control group, although the MABP was greater in the control group. Boezaart et al. ${ }^{(19)}$ did not find any differences between the esmolol and SNP groups. Nevertheless, these researchers noted that the esmolol group had a better VSF at the same MABP and that the SNP group re- quired a greater reduction in the MABP than the esmolol group to obtain the same VSF.

Guven et al. ${ }^{(22)}$ evaluated the effects of administering an infusion of a- 2 agonist (dexmedetomidine hydrochloride) from 10 minutes prior to surgery to the end of surgery. The placebo group was given saline solution. Both groups were administered the same induction and maintenance anaesthesia. The haematocrit and haemoglobin levels were recorded before surgery and 60 minutes after surgery. The intraoperative blood loss was evaluated by the surgeon according to the scales described by Fromme ${ }^{(18)}$ and Boezaart ${ }^{(19)}$. There was no significant difference in the operation time. The dexmedetomidine group exhibited a lower bleeding score than the control group. The HR was significantly lower in the dexmedetomidine group at the induction time and 1 and 20 minutes after induction. The MABP values were significantly lower in the dexmedetomidine group 5, 45, and 60 minutes after induction. The differences in the postoperative haemoglobin and haematocrit levels between the groups were not significant.

\section{D3) Studies comparing intravenous or inhaled central nervous} system depressants for the control of intraoperative bleeding Three types of drugs are used during general anaesthesia: a central nervous system depressant (intravenous or inhaled), an opioid analgesic (fentanyl, alfentanil, sufentanil, or remifentanil), and a muscle relaxant. Eight studies compared the use of an intravenous analgesic drug to an inhaled agent: six prospective studies ${ }^{(17,20,23,25,27,28)}$ and two retrospective studies ${ }^{(24,26)}$.

Beule et al. ${ }^{(23)}$ compared the use of propofol (+ fentanyl) with that of sevoflurane (+ fentanyl) on the total bleeding and VSF during surgery (according to a visual analog scale). These investigators did not find any difference in the bleeding, VSF, HR, or MABP between the groups, and a longer operation time was observed in the sevoflurane group.

Manola et al. ${ }^{(24)}$ compared three groups of patients who received different anaesthetics: propofol (+ remifentanil), sevoflurane (+ sufentanil), and isoflurane (+ fentanyl). These researchers obtained a higher amount of total bleeding with isoflurane $(+$ fentanyl) compared with sevoflurane (+ sufentanil) and propofol (+ remifentanil). The use of propofol (+ remifentanil) resulted in an improved VSF compared with the sevoflurane (+ sufentanil) and isoflurane (+ fentanyl) groups. If the MABP was less than 80 $\mathrm{mmHg}$, there were no differences between the groups. Wormald et al. ${ }^{(20)}$ compared patients that were administered propofol (+ remifentanil) or sevoflurane (+ fentanyl) and found a better VSF in the group that was administered the former compared with the group given the latter. There were no differences in the total duration of surgery and the HR. Moreover, these researchers found that the MABP was also associated with the visual field, i.e., a lower MABP was required by the group administered sevoflurane (+ fentanyl) to achieve a VSF similar to 
that found with the group given propofol (+ remifentanil). Eberhart et al. ${ }^{(17)}$ compared patients that were administered propofol (+ remifentanil) or isoflurane (+ alfentanil) and found a better VSF in the propofol (+ remifentanil) group, although the total bleeding was the same in both groups. In addition, the MABP was not different, and the HR was lower in the group given propofol (+ remifentanil).

Pavlin et al. ${ }^{(25)}$ compared patients administered propofol (+ alfentanil) or isoflurane (+ alfentanil) and obtained a better VSF with the group administered propofol (+ alfentanil), although the total bleeding was the same in both groups.

Blackwell et al. ${ }^{(26)}$ compared the effects of propofol (+ fentanyl or alfentanil) and isoflurane (+ fentanyl or alfentanil) and found less bleeding in the group given propofol (+ fentanyl or alfentanil) and no differences in the MABP. The two groups that were compared were not homogeneous because there were significant differences in both age and sex. Furthermore, these researchers did not differentiate between patients who used fentanyl as an analgesic and those who used alfentanil.

Ahn et al. ${ }^{(27)}$ compared the effects of propofol (+ remifentanil) and sevofluorane (+ remifentanil) and found less bleeding, a decrease in the HR, and an improvement of the VSF in the propofol group. The MABP and the duration of surgery were similar in both groups.

Tirelli el al. ${ }^{(28)}$ compared the effects of propofol (+ remifentanil) with those of isofluorane (+ fentanyl) and obtained a better VSF with propofol (+ remifentanil).

\section{Discussion}

Is general anaesthesia more effective than local anaesthesia at reducing intraoperative bleeding and complications? None of the studies ${ }^{(9-11)}$ considered the differences between local or general anaesthesia, and the patients were treated preoperatively using many different protocols. There was patient selection bias because those patients undergoing general anaesthesia were supposed to have more serious and extensive disease. Some authors, such as Hopkins et al. ${ }^{(29)}$ and Mortuaire et al. ${ }^{(30)}$, found an increase in complications in patients with more severe symptoms ${ }^{(29)}$ and with higher Lund-Mackay preoperative scores ${ }^{(29,30)}$. This finding, in addition to the fact that systemic anaesthetic agents are able to cause peripheral vasodilatation ${ }^{(31,32)}$, might have resulted in the higher amount of bleeding observed with patients administered general anaesthesia. There was also bias in terms of the longer operation time found for patients administered general anaesthesia because this time includes the time spent by the anaesthesiologist in induction and intubation and not only the time spent on the surgery itself.

Is the reverse Trendelenburg position an important factor in reducing intraoperative bleeding?

The study conducted by Ko et al. ${ }^{(12)}$ was methodologically consistent but did not explain how the authors calculated the 10 degrees. It would be necessary to compare the results with different reverse Trendelenburg position degrees. The head elevation decreases the MABP within the elevated region ${ }^{(33)}$ without affecting the cerebral perfusion pressure ${ }^{(34,35)}$.

Are preoperative and intraoperative pledgets with oxymetazoline, phenylephrine, cocaine, or epinephrine useful? It cannot be concluded whether oxymetazoline, phenylephrine, or cocaine is more effective than the others or even if they were effective at all. The study conducted by Riegle et al. ${ }^{(13)}$ only analysed children, and no scale was used for the assessment of bleeding. In addition, the method used to measure the bleeding was not explained, and there was no control group (patients that were administered none of the drugs) with which the results obtained for the drug-treated groups could be compared. Furthermore, the length of time that the patients were exposed to each of the pledgets prior and during surgery was not measured, and no technique was used to calculate the dose of each drug that was absorbed.

In the study conducted by Sarmento et al. ${ }^{(14)}$, there was no control group. The operation time varied widely between the groups, and the total amount of epinephrine applied topically was difficult to establish.

Is the preoperative infiltration of epinephrine and lidocaine into the pterygopalatine fossa useful?

We found only one article that analysed the effects of epinephrine and lidocaine injections into the pterygopalatine fossa. The study conducted by Wormald et al. ${ }^{(15)}$ was methodologically consistent and noted a clear improvement in the VSF in the infiltrated side.

\section{Can preoperative treatment be recommended?}

Steroids: Sieskiewicz et al. ${ }^{(2)}$ found that the VSF was improved and that the operation time was significantly shorter in patients who were administered prednisone. A relatively low dose of prednisone was used, and no other doses were used to determine the optimal dose needed.

$\beta$-blockers: Nair et al. ${ }^{(16)}$ did not always administer metoprolol 30 minutes before surgery. Because the half-life of this drug is limited, an exact comparison of the effects of the $\beta$-blocker between the different patients was not possible.

Vasodilators: In the study conducted by Jacobi et al. ${ }^{(21)}$, the SNP group was preoperatively administered captopril, which created a confounding factor, and SNP was administered on demand based on the need of maintaining the MABP between 65 and 75 $\mathrm{mmHg}$. In the study conducted by Boezaart et al. ${ }^{(19)}$, there was no control group with which to compare the usefulness or lack thereof of SNP and esmolol.

The use of $a-2$ agonists during the perioperative period has 
been associated with attenuated $H R$ and MABP ${ }^{(36)}$. Guven et al. ${ }^{(22)}$ found lower HR and MABP in the dexmedetomidine group, and it is possible that the administration of this drug caused less bleeding.

Is there any significant difference in the intraoperative field between patients who receive total intravenous anaesthesia and patients who receive inhaled anaesthesia?

Some studies focused on the anaesthetic used (intravenous or inhaled). However, as Beule et al. ${ }^{(23)}$ suggested, the differences between the groups might have been due to the analgesic agents used. The continuous infusion of remifentanil allowed a better control of the haemodynamic parameters, and this is not possible with fentanyl, which is administered in boluses. Remifentanil also has the effect of reducing the MABP and HR. Only three studies ${ }^{(23,25,27)}$ used the same analgesic in both groups. Pavlin et al. ${ }^{(25)}$ used labetalol on demand to reduce the $M A B P$, and did not indicate in which cases or in which groups this drug was used. Therefore, the beneficial effect of propofol cannot be established. In the study conducted by Ahn et al. (27) the MABP was maintained at $70-80 \mathrm{mmHg}$ by adjusting the amount of sevoflurane or propofol administered; however, if this adjustment failed, the remifentanil rate was adjusted based on the HR. The remainder of the studies ${ }^{(17,20,24,26,28)}$ used a different analgesic in each group, which hinders the comparisons among the groups. However, in all of these studies, a better VSF ${ }^{(17,20,24,27,28)}$ or less bleeding ${ }^{(24,26)}$ was found in the group with there was administered propofol and remifentanil.

All of the studies had limitations and were not entirely comparable with each other. In addition to the comparison of different combinations of analgesics and anaesthetics, the data collection was insufficient. Propofol was used for the induction of anaesthesia in all of the studies. The groups of patients analysed were very heterogeneous: some of the cases were new, and others were review cases. Beule et al. ${ }^{(23)}$ and Ahn et al. ${ }^{(27)}$ categorised their patients according to the scale developed by Lund and Mackay ${ }^{(37)}$, but most of the studies did not define the condition of the patient subjected to surgery.

Is it important to control the heart rate and mean arterial blood pressure during surgery?

Seven studies ${ }^{(12,15-17,20,22,27)}$ suggested that there is a direct relationship between the HR and the VSF. Although it is generally hypothesised, an association with MABP was not established. The bleeding produced in the nasal cavity during ESS is generally capillary bleeding. A reduced HR allows a greater emptying of the venous vessels, which reduces bleeding. This effect could justify the greater significance on bleeding of the HR compared with the MABP because the MABP is of greater importance on arterial origin but not as important in capillary and venous bleeding. Moreover, an MABP of less than $70 \mathrm{mmHg}$ can produce peripheral vasodilation and thus greater bleeding in the surgical field $(2,19,21,22,27,38)$.

What are the parameters that are usually measured during surgery?

To assess the VSF, most of the authors ${ }^{(2,12,15-17,19-22,24,28)}$ used the scale proposed by Fromme et al. ${ }^{(18)}$ and adapted the one described by Boezaart et al. ${ }^{(19)}$. This assessment method is not sufficiently discriminatory. Thus, although these differences were statistically significant in many cases, these were so small that it is difficult to estimate the results. Other authors used different scales ${ }^{(14,17,23,25,27)}$, and this parameter was not measured in some of the studies ${ }^{(9,10,26)}$.

To calculate the intraoperative bleeding, most authors measured the amount of blood stored by the aspiration system $(9-11,13,16,19,21,24-26)$. The total bleeding is difficult to quantify because part of it is swallowed by the patient and part remains in the aspiration system. In addition, when irrigation systems are used, blood and serum are mixed. In other studies, the bleeding was evaluated by processing the aspirated blood, by calculating different parameters ${ }^{(12,23)}$, or by the level of haemoglobin ${ }^{(17,22,27)}$. Of the three studies that measured the bleeding in a more sophisticated manner, two studies found no differences in the total bleeding between the groups ${ }^{(17,22)}$, and the other study found less blood loss in the propofol (+ remifentanil) group (27). Another factor to be considered is that the total bleeding depends directly on the duration of the surgery.

Few studies took into account the operation time $(2,9,10,12-15,20,22,23)$. However, the surgery duration was found to be related to the VSF, which could be justified by the vasodilating effect that general anaesthetics have throughout the operation time.

\section{Conclusions}

1. The literature presents no benefit of local anaesthesia compared with general anaesthesia in terms of intraoperative bleeding or complication rates.

2. The reverse Trendelenburg position can be recommended as a good and simple method for reducing the intraoperative blood loss without affecting the cerebral perfusion pressure, although the evidence supporting its use is poor.

3. Despite the widely held opinion in daily practise of the benefits of using pledgets with oxymetazoline, phenylephrine, or cocaine to prevent bleeding and to improve visualisation of the surgical field, there is not sufficiently strong evidence in the presently published literature to support this practise. The use of high doses of epinephrine $(1: 2,000)$ might reduce the blood loss compared with the use of lower doses, although the use of epinephrine can be dangerous due to its adverse effects, such as hypertensive peaks. The articles on this topic exhibited serious flaws in the methods used. 
4. The infiltration of phenylephrine and lidocaine into the pterygopalatine fossa might improve visualisation of the surgical field, although the evidence supporting this statement is poor.

5. The administration of prednisone at a dose of $30 \mathrm{mg} /$ day for five consecutive days prior to endoscopic surgery might improve the visibility of the operative field and shorten the operation time. However, more studies using different doses are needed to confirm these results.

6. The literature presents no benefits associated with the preoperative use of $\beta$-blockers or antihypertensive agents.

7. The use of dexmedetomidine hydrochloride before and during surgery might reduce the mean arterial blood pressure and heart rate and improve visualisation of the surgical field. These results are likely due to the close monitoring of the heart rate. However, the supporting evidence is poor, and further studies are needed.

8. It cannot be concluded that the use of propofol exerts benefits on improved bleeding control, improved visualisation of the surgical field, or avoiding complications compared with inhaled analgesics.

9. It has been suggested that remifentanil is a better anaesthetic than fentanyl.

10. A relationship between the heart rate and the visualisation of the operative field has been suggested. However, an association was not established with the mean arterial pressure.
11. A shorter operation time is associated with a better visualisation of the surgical field.

12. Patients with more severe symptoms and higher LundMackay preoperative scores appear to exhibit increased complications.

13. Other aspects that affect bleeding, such as alterations in coagulation and other patient comorbidities, were not considered in the studies. Most of the studies did not analyse the condition to be operated on, which causes bias and renders comparisons between the studies impossible. Healing and relapses were neither measured nor assessed in any of the studies.

14. All of the studies associated with bleeding control in ESS referred to its importance as a method for avoiding possible complications. However, only a few referred to the numbers of complications that occurred. None of the studies demonstrated that impaired visualisation due to bleeding influences the complication rate, as is understood in daily practise.

\section{Authorship contribution}

All of the authors actively participated in the literature review and the writing of the manuscript text.

\section{Conflict of interest}

No potential conflicts of interest have to be disclaimed.

\section{References}

1. Stankiewicz JA. Complications of endoscop ic sinus surgery. Otolaryngol Clin North Am. 1989; 22: 749-758.

2. Sieskiewicz A, Olszewska E, Rogowski M, Grycz E. Preoperative corticosteroid oral therapy and intraoperative bleeding during functional endoscopic sinus surgery in patients with severe nasal polyposis: a preliminary investigation. Ann Otol Rhinol Laryngol. 2006; 115: 490-494.

3. Cincikas D, Ivaskevicius J. Application of controlled arterial hypotension in endoscopic rhinosurgery. Medicina (Kaunas). 2003; 39: 852-859

4. Ayoglu H, Yapakci O, Ugur MB, Uzun L, Altunkaya H, Ozer $Y$, et al. Effectiveness of dexmedetomidine in reducing bleeding during septoplasty and tympanoplasty operations. J Clin Anesth. 2008; 20: 437-441.

5. Drozdowski A, Sieśkiewicz A, Siemiatkowski A. Reduction of intraoperative bleeding during functional endoscopic sinus surgery. Anestezjol Intens Ter. 2011; 43: 45-50.

6. Stammberger $\mathrm{H}$, Posawetz W. Functional endoscopic sinus surgery. Concept, indications and results of the Messerklinger technique. Eur Arch Otorhinolaryngol. 1990; 247: 63-76.
7. Stankiewicz JA. Complications of endoscopic intranasal ethmoidectomy. Laryngoscope. 1987; 97: 1270-1273.

8. Maniglia AJ. Fatal and other major complications of endoscopic sinus surgery. Laryngoscope. 1991; 101: 349-354.

9. Stankiewicz JA. Complications in endoscopic intranasal ethmoidectomy: an update. Laryngoscope. 1989; 99: 686-690.

10. Gittelman PD, Jacobs JB, Skorina J Comparison of functional endoscopic sinus surgery under local and general anesthesia. Ann Otol Rhinol Laryngol. 1993; 102: 289293

11. Gross RD, Sheridan MF, Burgess LP. Endoscopic sinus surgery complications in residency. Laryngoscope. 1997; 107: 10801085

12. Ko MT, Chuang KC, Su CY. Multiple analyses of factors related to intraoperative blood loss and the role of reverse Trendelenburg position in endoscopic sinus surgery. Laryngoscope. 2008; 118: 1687-1691.

13. Riegle EV, Gunter JB, Lusk RP, Muntz HR, Weiss KL. Comparison of vasoconstrictors for functional endoscopic sinus surgery in children. Laryngoscope. 1992; 102: 820-823.

14. Sarmento Junior KM, Tomita S, Kós AO. Topical use of adrenaline in different con- centrations for endoscopic sinus surgery. Braz J Otorhinolaryngol. 2009; 75: 280-289.

15. Wormald PJ, Athanasiadis T, Rees G, Robinson S. An evaluation of effect of pterygopalatine fossa injection with local anesthetic and adrenalin in the control of nasal bleeding during endoscopic sinus surgery. Am J Rhinol. 2005; 19: 288-292.

16. Nair S, Collins M, Hung P, Rees G, Close D, Wormald PJ. The effect of beta-blocker premedication on the surgical field during endoscopic sinus surgery. Laryngoscope. 2004: 114: 1042-1046.

17. Eberhart LH, Folz BJ, Wulf H, Geldner G. Intravenous anesthesia provides optimal surgical conditions during microscopic and endoscopic sinus surgery. Laryngoscope. 2003; 113: 1369-1373.

18. Fromme GA, Mackenzie RA, Gould AB, Lund BA, Offord KP. Controlled hypotension for orthognathic surgery. Anesth Analg. 1986 65: 683-686

19. Boezaart AP, van der Merwe J, Coetzee A. Comparison of sodium nitroprusside- and esmolol-induced controlled hypotension for functional endoscopic sinus surgery. Can J Anaesth. 1995; 42: 373-376.

20. Wormald PJ, van Renen G, Perks J, Jones JA, Langton-Hewer CD. The effect of the 
total intravenous anesthesia compared with inhalational anesthesia on the surgical field during endoscopic sinus surgery. Am J Rhinol. 2005; 19: 514-520.

21. Jacobi KE, Böhm BE, Rickauer AJ, Jacobi C, Hemmerling TM. Moderate controlled hypotension with sodium nitroprusside does not improve surgical conditions or decrease blood loss in endoscopic sinus surgery. J Clin Anesth. 2000; 12: 202-207.

22. Guven DG, Demiraran $Y$, Sezen $G$, Kepek $\mathrm{O}$, Iskender A. Evaluation of outcomes in patients given dexmedetomidine in functional endoscopic sinus surgery. Ann Otol Rhinol Laryngol. 2011; 120: 586-592.

23. Beule AG, Wilhelmi F, Kühnel TS, Hansen E, Lackner KJ, Hosemann W. Propofol versus sevoflurane: bleeding in endoscopic sinus surgery. Otolaryngol Head Neck Surg. 2007; 136: 45-50.

24. Manola M, De Luca E, Moscillo L, Mastella A. Using remifentanil and sufentanil in functional endoscopic sinus surgery to improve surgical conditions. ORL J Otorhinolaryngol Relat Spec. 2005; 67: 83-86.

25. Pavlin JD, Colley PS, Weymuller EA Jr, Van Norman G, Gunn HC, Koerschgen ME. Propofol versus isoflurane for endoscopic sinus surgery. Am J Otolaryngol. 1999; 20: 96-101.

26. Blackwell KE, Ross DA, Kapur P, Calcaterra TC. Propofol for maintenance of general anesthesia: a technique to limit blood loss during endoscopic sinus surgery. Am J Otolaryngol. 1993; 14: 262-266.
27. Ahn HJ, Chung SK, Dhong HJ, Kim HY, Ahn $\mathrm{JH}$. Comparison of surgical conditions during propofol or sevofluorane anaesthesia for endoscopic sinus surgery. Br J Anaesth. 2008; 100: 50-54.

28. Tirelli G, Bigarini S, Russolo M, Lucangelo U, Guillo A. Total intravenous anaesthesia in endoscopic sinus-nasal surgery. Acta Otorhinolaryngol Ital. 2004; 24: 137-144.

29. Hopkins C, Browne JP, Slack R, Lund VJ, Topham J, Reeves BC, et al. Complications of surgery for nasal polyposis and chronic rhinosinusitis: the results of a national audit in England and Wales. Laryngoscope. 2006; 116: 1494-1499.

30. Mortuaire G, Bahij J, Maetz B, Chevalier D. Lund-Mackay score is predictive of bleeding in ethmoidectomy for nasal polyposis. Rhinology. 2008; 46: 285-288.

31. Koch M, Backer D De, Vincent JL, Barvais L, Hennart D, Schmartz D. Effects of propofol on human microcirculation. $\mathrm{Br} J$ Anaesth. 2008; 101: 473-478.

32. Robinson BJ, Ebert TJ, O'Brien TJ, Colinco MD, Muzi M. Mechanisms whereby propofol mediates peripheral vasodilation in humans. Sympathoinhibition or direct vascular relaxation? Anesthesiology. 1997; 86: 64-72.

33. Simpson P. Perioperative blood loss and its reduction: the role of the anaesthetist. $\mathrm{Br}$ J Anaesth. 2002; 69: 498-507.

34. Tankisi A, Rasmussen M, Juul N, Cold GE. The effects of 10 degrees reverse Trendelenburg position on subdural intracranial pressure and cerebral perfusion pressure in patients subjected to craniotomy for cerebral aneurysm. J Neurosurg Anesthesiol. 2006; 18: 11-17.

35. Rolighed Larsen JK, Haure P, Cold GE. Reverse Trendelenburg position reduces intracranial pressure during craniotomy. J Neurosurg Anesthesiol. 2002; 14: 16-21.

36. Ebert TJ, Hall JE, Barney JA, Uhrich TD, Colinco MD. The effects of increasing plasma concentrations of dexmedetomidine in humans. Anesthesiology. 2000; 93: 382-394.

37. Lund VJ, Mackay IS. Staging in rhinosinusitus. Rhinology. 1993; 31: 183-184.

38. Lassen NA, Christensen MS. Physiology of cerebral blood flow. Br J Anaesth. 1976; 48: 719-734.

\section{Antonio Rodríguez Valiente \\ $\mathrm{C} / J$ oaquin Rodrigo, 2 \\ 28222 Majadahonda \\ Madrid \\ Spain}

Tel: +34-629-73 6619

+34-91-1916000

Fax: +34-91-373 0535

E-mail: arova777@gmail.com 